\title{
Strange (and incompatible) bedfellows: The relationship between the National Health Act and the regulations relating to artificial fertilisation of persons, and its impact on individuals engaged in assisted reproduction
}

\author{
C van Niekerk, LLB, LLM \\ Department of Private Law, Faculty of Law, University of the Western Cape, Cape Town, South Africa
}

Corresponding author: C van Niekerk (cavanniekerk@uwc.ac.za)

\begin{abstract}
Individuals are increasingly having recourse to assisted or artificial reproduction in order to realise their desire for offspring. This field is currently regulated by the National Health Act No. 61 of 2003 (NHA, or the Act) and the regulations relating to artificial fertilisation of persons, which form the framework legislation for assisted reproduction. Individuals having recourse to assisted reproductive technologies are therefore forced to engage with this legislation in one way or another. The challenge posed by the current legislative framework is that both the Act and the regulations are unclear and confusing. One could even go so far as to say that they are incompatible in some respects. Matters are further complicated when the Act and the regulations have to be applied alongside legislation such as the Children's Act No. 38 of 2005. The result is that legislation that is intended to provide legal certainty and clarity has the opposite result. This article considers the Act, its regulations and legislation that has bearing on assisted forms of reproduction. The aim of this analysis is to identify flaws and to provide suggestions for remedying potential defects, in order to produce legislation that not only creates legal certainty, but that is up to date and on par with advances in science and technology.
\end{abstract}

S Afr J Bioethics Law 2017;10(1):32-35. DOI:10.7196/SAJBL.2017.v10i1.524

The desire to produce offspring is as old as time. It is, in some instances, even considered integral to our identity as human beings. However, the reality exists that not everyone who desires offspring is able to reproduce naturally. There are those who are forced to resort to assisted reproduction to fulfil this desire. For them, the process of becoming parents is often not a smooth one. A road paved with a myriad of choices awaits them. These include decisions regarding doctors, procedures and possibly donors. This process is further complicated by the existence of legislation which, instead of providing clarity on the options available to them, has the opposite effect. The legislation in question is the National Health Act No. 61 of 2003 (NHA, or the Act) ${ }^{[1]}$ and the regulations relating to artificial fertilisation of persons ('the regulations') ${ }^{[2]}$ promulgated under the NHA. This Act has been characterised as 'flawed law, ${ }^{\prime[3]}$ and the regulations are no different. What makes matters worse is the fact that some acts are reliant on these regulations in order to give them content. What follows is therefore an analysis of the NHA, the regulations and the Children's Act No. 38 of $2005,[4]$ the aim of which is to identify flaws and to provide suggestions for remedying potential defects, in order to produce legislation that not only creates legal certainty, but which is up to date and on par with advances in science and technology.

\section{The NHA}

The NHA was promulgated as a replacement for 'the last vestige of apartheid in health policy'. It:

'provides a framework for a structured and uniform health system under which the various elements of the South African
(SA) national health system may be united in the common goal of improving universal access to quality health' ${ }^{[5]}$

The Act, consisting of 12 chapters, relies heavily on regulations to supplement its provisions. Chapter 8 alone has produced no less than 14 regulations $^{[3]}$ since it first entered into force on 1 March 2012. The reason for this is attributed to the fact that the NHA is:

'framework legislation. This means that it sets out broad legal and operational principles that must be fleshed out in regulations ${ }^{\text {[5] }}$

While this may be true, what is alarming is the fact that the numerous regulations were promulgated within a relatively short period of 5 years, which is both excessive and unacceptable. ${ }^{[3]}$ This 'proverbial flooding of the legislative plain' is indicative of the fact that chapter 8 is 'fatally flawed! ${ }^{[3]}$ It is further:

'outdated and lags behind scientific development and progress, ... contains factual errors, creates lacunae and hands the minister of health excessive authority and power. ${ }^{\prime[3]}$

The first flaw identified can be found in section 55. This section, titled the 'removal of tissue, blood, blood products or gametes from living persons' states that '[a] person may not remove ... gametes from the body of another living person'. It is interesting to note that while this provision requires consent from the donor, it limits the removal of gametes to living persons only. The challenge posed by this provision and the flaw inherent herein is discussed with reference to section 56. 
Section 56 provides that tissue, blood, blood products or gametes removed or withdrawn from living persons may only be used for such medical and dental purposes as may be prescribed. Artificial fertilisation is presumably a prescribed medical purpose. This assumption is drawn from the existence of an entire set of regulations dedicated to artificial fertilisation. Given the fact that it is medically possible to remove or withdraw tissue, blood, blood products or gametes from both the living and the dead (within certain time frames), it is interesting that section 55 limits the removal of gametes to the living. It is in this respect that chapter 8 of the NHA is 'outdated and lags behind scientific development and progress. $\left.{ }^{\prime}\right]$ Evidence of this can be found in developments pertaining to assisted reproduction. Katz, ${ }^{[6]}$ for example, observes that:

'[f]or over 30 years it has been possible to retrieve sperm from males who are deceased, brain dead, comatose or in a persistent vegetative state for use in procreation by the recipient. ${ }^{\prime[6]}$

In fact, the first reported case of posthumous sperm retrieval occurred in 1980, which is more than 20 years prior to the promulgation of the NHA. That it is still not permitted under the NHA either confirms that the Act is outdated, in comparison with countries such as Israel, Belgium and the UK, where posthumous reproduction is allowed, or alternatively, it suggests that there are other reasons for ignoring the possibilities offered by these scientific developments.

Another criticism levelled against this section pertains to the ministerial authorisation for the removal or withdrawal of tissue, blood, a blood product or gametes. The problem with this provision is that:

'ministerial approval is not ideal as the minister, or the delegated person acting on his or her behalf, often lacks the necessary knowledge regarding [assisted reproduction and assisted reproductive technologies to make an informed decision]. This may inhibit decision-making and ultimately has negative repercussions on the development of this branch of science in South Africa! ${ }^{[3]}$

It has been suggested, within the context of stem-cell research, that an independent body or specialist regulatory board be established to deal with such matters. ${ }^{[3]}$ This recommendation applies equally to assisted reproduction and developments involving assisted reproductive technologies (ARTs). An independent body would be beneficial as this body could objectively assess which new developments within ART should be permitted, without undue influence from any entity with a vested interest in the outcome. Furthermore, all legislation involving technical areas such as ART should not be drafted exclusively by legal 'experts'. The obvious lack of understanding displayed in the existing legislation suggests that medical expertise is a necessity in legislation of this nature, something which is clearly lacking. It has been suggested that:

'[t]he importance of interdisciplinary co-operation in the drafting, interpretation and implementation of legislation in this area cannot be overemphasised. ${ }^{[7]}$

Section 57 serves as a prohibition on reproductive cloning. This term is defined in section 57(6)(a) as:

'the manipulation of genetic material in order to achieve the reproduction of a human being and includes nuclear transfer or embryo splitting for such purpose'.

The problem posed by this provision is that other forms of genetic manipulation have developed that are not performed for the purpose of reproductive cloning. Mitochondrial donation or transfer is one such development. This treatment allows for the removal of DNA 'from a patient's egg or embryo containing unhealthy mitochondria to a donor's egg or embryo containing healthy mitochondria.[8] Based on the definition provided, there is a degree of manipulation of the genetic material, as well as activity involving nuclear transfer. Such activity is ostensibly a violation of section 57 . Bredenoord et al., ${ }^{\left[{ }^{[9]}\right.}$ however, disagree. They are of the opinion that a transfer of mitochondria does not produce genetically identical offspring. As such, mitochondrial transfer does not constitute reproductive cloning ${ }^{[9]}$ and should therefore be permitted.

What is evident from the current framing of section 57 is that it leaves unanswered the status of newer developments involving assisted reproduction. In this respect, the legislator would do well to amend the provision to provide clarity on the status of genetic manipulation conducted for reproductive, non-cloning purposes. Such an amendment could specifically define and identify permissible forms of genetic manipulation conducted for reproductive, noncloning purposes.

Section 62(1)(a)(iii) of the NHA states that:

'a person who is competent to make a will may ... donate his or her body or any specified tissue thereof to be used after his or her death'.

While this provision could have been interpreted as allowing posthumous gamete retrieval and subsequent reproduction, this possibility is quashed by the definition in the act that defines tissue as 'human tissue ... [which] excludes blood or a gamete.' This particular provision therefore puts paid to the possibility of posthumous reproduction.

\section{The regulations}

\section{Considering that:}

'the Act is flawed [a] person would thus wish to see these flaws addressed in the numerous regulations made in terms of the NHA. This is, however, not the case as the regulations have, rather than [clarified] some of the ambiguities and solved some of the issues, caused even further complications. ${ }^{\prime[3]}$

This is sadly the case regarding the regulations relating to the artificial fertilisation of persons, despite the fact that these regulations have recently been amended. A number of flaws have been identified, which raises some concern for the use of assisted reproduction. The first apparent flaw can be found in the title. The use of the term 'artificial'suggests that the process is an unnatural one. For individuals who pursue this option, it may be a last resort - and often a painful and difficult one, which should not be laden with negative connotations in the terminology used. It is suggested that the title be amended to the 'regulations relating to the assisted reproduction of persons'. A revision would clearly indicate the purpose for which these forms of ART are used. The term 'assisted' is also broad enough to include newer technologies that do not involve fertilisation but which are still integral to reproduction. 
The second set of flaws lies in the definition section. This section defines artificial fertilisation as 'the introduction by other than natural means'. Once again, this is a value judgement from persons who may not have grappled with infertility ${ }^{[10,11]}$ or subfertility. ${ }^{[12]}$

Additional definitions that are a cause of concern include 'deceased'. This term is not used anywhere in the regulations, except in the definition section. Furthermore, the NHA defines 'death' as being brain dead. In contrast, the regulations define 'deceased' as meaning 'somatic death'. While these terms mean the same thing, it is interesting to note that the regulations on more than one occasion opt for a more complex definition that does nothing in the way of providing clarity or understanding.

Furthermore, in the definition of gamete donor, reference is made only to living persons. This once again suggests that a gamete donor may not be a deceased person, regardless of whether consent has been obtained or not. The option of posthumous reproduction is thus ostensibly excluded.

The third flaw pertains to section 2 of the regulations, which unequivocally links the regulations to the withdrawal of gametes from living persons. The existence of this provision suggests that gametes may not be retrieved from deceased persons. Sadly, the exclusion of posthumous gamete retrieval (regardless of whether consent was given prior to death) means that for some individuals (such as a spouse who desires offspring that are biologically related to the deceased), this may represent a lost opportunity to reproduce entirely.

Section 13 deals with pre-implantation and prenatal testing for sex selection. This provision indicates that this procedure is prohibited (except in clearly defined instances), but is silent on the issue of whether it is permitted in other instances such as pre-implantation genetic diagnosis (PGD), for the purpose of creating saviour siblings. However, this is potentially covered in the regulations regarding the use of human DNA, RNA, cultured cells, stem cells, blastomeres, polar bodies, embryos, embryonic tissue and small-tissue biopsies for diagnostic testing, health research and therapeutics. ${ }^{[13]}$ What is interesting to note is that while these regulations relate to diagnostic testing, the creation of saviour siblings involves artificial fertilisation, ${ }_{,}^{\prime[13]}$ and is performed for the purpose of reproduction. The issue of PGD should as such be covered in the regulations, if only to advise prospective users of 'artificial fertilisation' that this option is not permitted by law.

Section 17 of the regulations deals with those instances where it comes to the attention of the parents that a child born as a result of ART suffers from an illness or defect. Presumably this provision relates to those instances where donor gametes have been used. This provision states that these defects or illnesses must be brought to the attention of the institution that effected the artificial fertilisation. The purpose of this notification is unclear. It raises the important question of whether liability will ensue and if so, who will be held liable: the institution or the donor? While the institution may be covered against financial claims of this nature, the possibility of delictual or contractual damages against donors may impact on the use of ART to facilitate reproduction.

Section 18 deals with the issue of the ownership of gametes, zygotes and embryos. This provision states that ownership of a zygote or embryo, after fertilisation has occurred, vests in the recipient regardless of whether the donor is male or female. The challenge posed by this provision is that a zygote or embryo is the genetic product of two individuals. It is thus unclear whether the recipient is the male donor or female donor. Furthermore, in instances where zygotes or embryos have been cryopreserved and there is no identified recipient, in other words, where the genetic parents are uncertain whether they will use the zygote or embryo themselves, who does ownership belong to? The regulations on this score are unclear, and there is definitely room for legislative reform. While the regulations state that embryos will be discarded if a period of 10 years has passed and the embryos have not been claimed, the situation regarding the ownership of embryos where there is a dispute between the parties is similarly unclear.

Clearly the regulations are as perplexing as chapter 8 of the NHA is 'confusing and incomplete.'.14]

That said, the 2016 regulations are an improvement on the 2012 regulations ${ }^{[15]}$ in at least two respects. Firstly, the term 'surrogacy', as defined in the 2012 regulations, has been omitted. The definition of this term had served as a source of confusion, as it did not appear to contemplate traditional or partial surrogacy. This was inconsistent with the Children's Act, which provides for full or gestational as well as traditional or partial surrogacy. The definition was further problematic as it referred to 'contractual parents', which was a deviation from the 'commissioning parents' referred to in the Children's Act. What is interesting to note in this regard is that the 2012 regulations were drafted after the Children's Act was promulgated, and yet this appeared to have been done in isolation and without any regard for the legislation that would impact on them.

Secondly, section 6 of the 2012 regulations was a flawed and outdated provision. This section restricted the donation of gametes to a maximum of six children being conceived using the same gamete donor. The problem with this limitation was twofold. Firstly, there is a difference between the conception of six children, and six live births. ${ }^{[16]}$ If the intention of the legislator was the latter as opposed to the former, then this intention was not relayed in the wording of section 6 . Secondly, the number six was arbitrary and inconsistent with international trends. ${ }^{[16]}$ The UK, for example, currently limits the use of donor gametes to 10 live births, while the Netherlands limits their use to $25 .{ }^{[16]}$ In both these instances, the number arrived at was the result of country-specific population data. ${ }^{[16]}$ Fortunately, this provision has since been replaced by section 7 of the 2016 regulations, which restricts the donation of gametes to 12 live births, and even permits this number to be exceeded to allow a family to have an additional child from the same donor. This is a marked improvement on the previous position.

Despite the improvements listed above, the incompatibility between the NHA and the regulations does not end there. The Children's Act refers to certain forms of assisted reproduction in its provisions, which further highlights the lack of compatibility mentioned above.

\section{The Children's Act}

As the Children's Act was promulgated after the NHA and before the regulations entered into force, one would expect that the Children's Act would complement the NHA or that the regulations would complement the Children's Act. While this is seemingly the case with all the provisions dealing with assisted reproduction, namely sections 40 and 41 of the Children's Act, which relate to children 
conceived by artificial fertilisation, and chapter 19, which deals with surrogacy, it is not the case as far as the definitions are concerned. For example, artificial fertilisation is defined differently in the Children's Act than it is in the regulations. In the Children's Act, the emphasis is more on the way in which reproduction can occur than it is on the procedures by which it can occur. In addition, the term 'surrogate' in the Children's Act is wide enough to accommodate both full and partial surrogacy, which was not the case in the definition provided for in the 2012 regulations. As mentioned, the now-removed definition of surrogate referred to 'contracting parents'. This was inconsistent with the preferred term of 'commissioning parents' in the Children's Act. Interestingly, the 2016 regulations omit the term entirely. This is worrying, as the NHA makes no reference to the term, and surrogacy involves artificial fertilisation. At the very least, this term should have been included in the 2016 regulations, although in an amended form.

While these inconsistencies are not fatal as far as assisted reproduction is concerned, they do suggest an incompatibility in the existing legislative framework, one which has the potential to frustrate those who engage in this form of reproduction.

\section{Recommendations}

One of the challenges posed by assisted reproduction or the use of ART is the issue of how best to regulate it. In some instances, countries such as the UK have a system of regulation in place that attempts to address all concerns involving the use of ART. ${ }^{[17]}$ In contrast, countries such as the USA adopt a very different approach, where there is minimal federal legislation. ${ }^{[17]}$ Instead, there is a heavy reliance on guidelines that serve as guideposts for matters pertaining to ART. SA appears to be midway between these two extremes, and yet the legislation that exists is not comprehensive enough to adequately address the concerns raised, or to deal with newer developments in this field. What is therefore needed is a review of all legislation dealing with ART. The purpose of this would be to create comprehensive legislation that adequately governs this area. A model similar to that adopted by Canada is proposed. While the Canadian Assisted Human Reproduction Act of 2004 was struck down by the Supreme Court of Canada for 'invading provincial jurisdiction, ${ }_{1}^{\prime[18]}$ there is much that can be learnt from this model. One of the striking features of the Assisted Human Reproduction Act was the fact that it 'addressed five of six major areas that constitute the typical policy space with respect to ARTs.'[18] These included embryonic research, reproductive cloning, assisted conception, surrogacy and offspring engineering. The only area omitted relates to the parentage policy, an area that is included in the UK's ART legislation. ${ }^{[19]}$
The second recommendation relates to the creation of an independent regulatory body, similar to the UK's Human Fertilisation and Embryology Authority, which would have oversight over matters related to ART, and in particular, new technological advancements.

These two changes alone would go a long way toward creating legal certainty for those engaged in assisted reproduction, and toward ensuring that SA stays abreast of developments in the field.

1. South Africa. National Health No. Act 61 of 2003

2. South Africa. National Health No. Act 61 of 2003. Regulations Relating to Artificial Fertilisation of Persons. Government Gazette No. 40312, 30 September 2016.

3. Prinsen L. Flawed law: A critical analysis of the faults and shortcomings of Chapter 8 of the National Health Act of 2003. Obiter 2013;34(3):522-532.

4. South Africa. Children's Act No. 38 of 2005

5. Ministry of Health. Briefing by Minister of Health, Dr Manto Tshabalala-Msimang on the National Health Act, 19 August 2004. http://www.polity.org.za/article/ tshabalalamsimang-national-health-act-19082004-2004-08-19 (accessed 7 March 2017).

6. Katz KD. Parenthood from the grave: Protocols for retrieving and utilizing gametes from the dead or dying. Univ Chic Leg Forum 2006;1:289-316.

7. Pepper MS. Medicine and the law: Partial relief from the regulatory vacuum involving human tissues through enactment of chapter 8 of the National Health Act and regulations thereto. S Afr Med J 2012;102(9):736-737. https://doi. org/10.7196/samj.5940

8. Human Fertilisation and Embryology Authority. Mitochondrial donation: An introductory briefing note. United Kingdom: Human Fertilisation and Embryology Authority, 1 October 2014. http://www.hfea.gov.uk/docs/201410-01_Mitochondrial_donation_an_introductory__ briefing_note_-_final.pdf (accessed 16 June 2016).

9. Bredenoord AL, Pennings G, de Wert G. Ooplasmic and nuclear transfer to prevent mitochondrial DNA disorders: Conceptual and normative issues. Hum Reprod Update 2008;14(6):669-678. http://dx.doi.org/10.1093/humupd/dmn035

10. World Health Organization. Infertility Definitions and Terminology. World Health Organization, 2016. http://www.who.int/reproductivehealth/topics/infertility/ definitions/en/ (accessed 7 March 2017).

11. Kruger TF, Botha MH. Clinical Gynaecology. 4th ed. Cape Town: Juta, 2011:337.

12. Gnoth C, Godehardt E, Frank-Herrmann F, Friol K, Tigges J, Freundl G. Definition and prevalence of subfertility and infertility. Hum Reprod 2005;20(5):1144-1147. http://doi.org/humrep/deh870

13. Du Plessis E, Govindjee A, van der Walt G. A legal analysis of 'saviour siblings' and 'benefactor children' in South Africa. Obiter 2014;35(2):224-253.

14. Pepper MS. Cell-based therapy - navigating troubled waters. S Afr Med 2010;100(5):286-288. https://doi.org/10.7196/samj.4131

15. South Africa. National Health No. Act 61 of 2003. Regulations Relating to Artificial Fertilisation of Persons. Government Gazette No. 35099, 2 March 2012. (Published under Government Notice R175).

16. Dhai A. Editorial: Limiting donor conceptions to six: Time for change. S Afr Bioeth Law 2014:7(1):2-3. https://doi.org/10.7196/sajbl.322

17. Stenger RL. The law and assisted reproduction in the United Kingdom and United States. J Law Health 1994;9(1):135-160.

18. Snow D, Knopff R. Assisted reproduction policy in federal states: What Canada should learn from Australia. University of Calgary: School of Public Policy, 2012. http://www.policyschool.ucalgary.ca/sites/default/files/research/dave-snowart-final.pdf (accessed 29 June 2016).

19. United Kingdom. Human Fertilisation and Embryology Act of 1990. United Kingdom, Parliament, 1990. http://www.legislation.gov.uk/ukpga/1990/37/ contents (accessed 7 March 2017). 